\title{
"PROMOSI KESEHATAN PERILAKU HIDUP BERSIH DAN SEHAT" DI SD 3 SIDOREJO PANGKALAN BUN
}

\author{
${ }^{1}$ Lieni Lestari \\ ${ }^{1}$ STIKes Borneo Cendekia Medika \\ ${ }^{1}$ Email : lienilestari@gmail.com
}

\begin{abstract}
ABSTRAK
Perilaku Hidup Bersih dan Sehat merupakan cerminan pola hidup keluarga yang senantiasa memperhatikan dan menjaga kesehatan seluruh anggota keluarga. Anak usia sekolah merupakan kelompok usia yang kritis, karena pada usia tersebut seorang anak rentan terhadap masalah kesehatan. Selain rentan terhadap masalah kesehatan, anak usia sekolah juga berada pada kondisi yang sangat peka terhadap stimulus sehingga mudah dibimbing, diarahkan, dan ditanamkan kebiasaan-kebiasaan yang baik, termasuk kebiasaan berprilaku hidup bersih dan sehat. Pada umumnya, anak-anak seusia ini juga memiliki sifat selalu ingin menyampaikan apa yang di terima dan diketahuinya dari orang lain. Perilaku hidup bersih dan sehat (PHBS) adalah sekumpulan perilaku yang dipraktikkan atas dasar kesadaran sebagai hasil pembelajaran, yang menjadikan seseorang, keluarga, kelompok atau masyarakat mampu menolong dirinya sendiri dibidang kesehatan dan berperan aktif dalam mewujudkan kesehatan masyarakat.

Sasaran strategis dari kegiatan ini adalah pelajar SDN 3 Sidorejo, pelajar SDN 3 Sidorejo dianggap strategis karena pada usia ini adalah usia yang masih belum memiliki pengetahuan yang baik tentang PHBS serta sering terpapar dengan makanan dan jajanan yang kurang sehat. Metode dalam kegiatan pengabdian ini yaitu melakukan penyuluhan dengan materi Perilaku Hidup Bersih dan Sehat menggunakan LCD, kemudian dilanjutkan demonstrasi dan tanya jawab. Saat penyuluhan anak-anak mendengarkan pemaparan materi dengan tertib. Setelah penjelasan materi Perilaku Hidup Bersih dan Sehat tim penyuluh melakukan sesi tanya jawab singkat sebagai bentuk evaluasi kegiatan. Kemudian kegiatan ditutup oleh wali kelas 5 SDN 3 Sidorejo.
\end{abstract}

\section{Kata kunci : PHBS, Kesehatan, Pelajar}

\begin{abstract}
Clean and healthy living behavior is a reflection of the family pattern that is continuously watching and guarding the rest of the family health.Children of school age is a critical age group, because of that age a child vulnerable to health problems. Other than vulnerable to health problems, children of school age are also on condition that was very sensitive to a stimulus so that it can easily be guided, directed, and a good implanted,including the habit of pretending to clean and healthy living. In general, children under that age also having the nature of always wanted to convey that received and he knew from others. Perilaku hidup bersih and healthy life been a set of behavior that put into practice on the basis of consciousness as lessons then, lest you keep, the family, group or community to help him in the fields of health and play an active role in realizing community health. Strategic objective of this activity is students sdn 3 sidorejo, students sdn 3 sidorejo considered strategic because it at the age of it is ages that are still not yet having knowledge both with respect to phbs and often exposed to food and unhealthy hawker. This is the method in the activities of devotion to provide counseling with matter clean and healthy living behavior use lcd, these were then followed demonstrations and a question and answer session. The counseling was held
\end{abstract}


children listen to an examination of materials with the orderly.After material explanation clean and healthy living behavior extension workers team do a question and answer session short a period as the form of evaluate activities.Then closed the fifth graders activities by the wali sidorejo sdn 3 .

Keyword: phbs, health, students

\section{Pendahuluan}

Perilaku Hidup Bersih dan Sehat merupakan cerminan pola hidup keluarga yang senantiasa memperhatikan dan menjaga kesehatan seluruh anggota keluarga. Semua perilaku kesehatan yang di lakukan atas kesadaran sehingga anggota keluarga atau keluarga dapat menolong dirinya sendiri dibidang kesehatan dan dapat berperan aktif dalam kegiatankegiatan kesehatan di masyarakat merupakan pengertian lain dari PHBS.

Anak usia sekolah merupakan kelompok usia yang kritis, karena pada usia tersebut seorang anak rentan terhadap masalah kesehatan. Selain rentan terhadap masalah kesehatan, anak usia sekolah juga berada pada kondisi yang sangat peka terhadap stimulus sehingga mudah dibimbing, diarahkan, dan ditanamkan kebiasaankebiasaan yang baik, termasuk kebiasaan berprilaku hidup bersih dan sehat. Pada umumnya, anak-anak seusia ini juga memiliki sifat selalu ingin menyampaikan apa yang di terima dan diketahuinya dari orang lain.

Berdasarkan hasil riset masih cukup banyak penduduk yang belum menerapkan perilaku hidup bersih dan sehat, walaupun ada kecenderungan perbaikan. Berdasarkan analisis kecenderungan secara rerata nasional, terdapat peningkatan proporsi penduduk berperilaku cuci tangan secara benar pada tahun 2013 yaitu 47,0\% dibandingkan tahun 2007 yaitu
23,2\%. Demikian pula dengan perilaku $\mathrm{BAB}$ benar terjadi peningkatan dari $71,1 \%$ pada tahun 2007 menjadi $82,6 \%$ pada tahun 2013. Untuk perilaku benar dalam menyikat gigi berkaitan dengan faktor gender, ekonomi, dan daerah tempat tinggal, ditemukan sebagian besar penduduk Indonesia menyikat gigi pada saat mandi pagi maupun mandi sore, $(76,6 \%)$. Menyikat gigi dengan benar adalah setelah makan pagi dan sebelum tidur malam, untuk Indonesia ditemukan hanya 2,3\%.

Anak usia sekolah dasar juga sangat rentan mengalami masalah kesehatan karena pola makan yang tidak sehat. Makanan yang dijual disekolah maupun dilingkungan sekolah belum semua memenuhi standar kesehatan dan keamanan, dan anak sekolah cenderung lebih menyukai makanan yang tidak sehat baik karena pengetahuan yang belum memadai atau karena mudah terpengaruh oleh iklan. Sehingga semakin banyak terjadi kegemukan atau kelebihan berat badan akibat konsumsi makanan yang tinggi kalori.

\section{Metode}

Sasaran strategis dari kegiatan ini adalah pelajar SDN 3 Sidorejo, pelajar SDN 3 Sidorejo dianggap strategis karena pada usia ini adalah usia yang masih belum memiliki pengetahuan yang baik tentang PHBS serta sering terpapar dengan makanan dan jajanan yang kurang sehat. Metode dalam kegiatan pengabdian ini yaitu 
melakukan penyuluhan dengan materi Perilaku Hidup Bersih dan Sehat menggunakan LCD, kemudian dilanjutkan demonstrasi dan tanya jawab.

\section{Hasil dan Pembahasan}

Kegiatan pengabdian masyarakat ini dilaksanakan pada hari Jumat tanggal 22 September 2018 mulai pukul 09.00 WIB. Jumlah siswa siswi kelas 5 SDN 3 Sidorejo yang mengikuti penyuluhan adalah 40 orang.

Kegiatan dimulai dengan pembukaan oleh Kepala Sekolah SDN 3 Sidorejo, dilanjutkan dengan perkenalan dari dosen STIKes Borneo Cendekia Medika oleh wali kelas 5 SDN 3 Sidorejo. Penyuluhan dibuka oleh Ketua Tim yang memberikan materi penyuluhan Perilaku Hidup Bersih dan Sehat.

Saat penyuluhan anak-anak mendengarkan pemaparan materi dengan tertib. Setelah penjelasan materi Perilaku Hidup Bersih dan Sehat tim penyuluh melakukan sesi tanya jawab singkat sebagai bentuk evaluasi kegiatan. Kemudian kegiatan ditutup oleh wali kelas 5 SDN 3 Sidorejo. Kegiatan berakhir pada pukul 12.30 WIB.

\section{Kesimpulan dan Saran Kesimpulan}

Perilaku hidup bersih dan sehat (PHBS) adalah sekumpulan perilaku yang dipraktikkan atas dasar kesadaran sebagai hasil pembelajaran, yang menjadikan seseorang, keluarga, kelompok atau masyarakat mampu menolong dirinya sendiri dibidang kesehatan dan berperan aktif dalam mewujudkan kesehatan masyarakat.
Manfaat Perilaku Hidup Bersih dan Sehat (PHBS) di sekolah antara lain: Terciptanya sekolah yang bersih dan sehat sehingga peserta didik, guru, dan masyarakat lingkungan sekolah terlindungi dari berbagai gangguan dan ancaman penyakit, meningkatnya semangat proses belajar-mengajar yang berdampak pada prestasi belajar peserta didik, citra sekolah sebagai institusi pendidikan semakin meningkat sehingga mampu menarik minat orang tua (masyarakat) untuk menyekolahkan anaknya di sekolah tersebut, meningkatnya citra pemerintah daerah di bidang pendidikan, dan menjadi percontohan sekolah sehat bagi daerah lain.

Saran

Untuk kedepannya dapat dilakukan penyuluhan Perilaku Hidup Bersih dan Sehat di seluruh kelas agar pengetahuan siswa-siwi tentang PHBS dapat merata dan diaplikasikan di kehidupan sehari-hari.

\section{Daftar Pustaka}

Ateng, A.K. (1994). Azas dan Landasan Pendidikan Jasmani. Jakarta: Depdikbud Dirjen Dikti.

Hidayat Taufik.(2013). Perilaku Hidup Sehat Siswa Kelas IV dan V di Sekolah Dasar Negeri Numpudadi Kecamatan Petanahan Kabupaten Kebumen. Skripsi. Yogyakarta: FIK UNY.

Media Pendidikan Indoesia. 2014. Perilaku Hidup Bersih dan Sehat (PHBS). Access : http://www.medukasi.web.id/2014/07/perilakuhidup-bersih-dan-sehat-phbsdi.html

Menkes RI. (2011). Pedoman Pembinaan Perilaku Hidup Bersih Sehat. Diakses dari 
http://www.promkes.depkes.go.i d/dl/pedoman_umum_PHBS.pdf.

Pratiwi, N.S. (2008). Hubungan Pengetahuan dan Sikap terhadap Perilaku Hidup Bersih Sehat (PHBS) Siswa SD Negeri Ngebel Kasihan Bantul. Yogyakarta: UMY.

Promkes. (2016). Perilaku Hidup Bersih Sehat. Diakses dari http://promkes.depkes.go.id/peril aku-hidup-bersih-dan-sehat-disekolah.

Suryaningsih Imelda. (2014). Cara Cuci Tangan yang Benar. Diakses dari http://www.readersdigest.co.id/se hat/info.medis/cara.cuci.tngan.ya ng.benar/005/001/260. 